IJAMSR 3 (1) www.ijamsr.com CrossRef: https://doi.org/10.31426/ijamsr.2020.3.1.3011

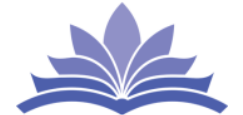

I J A M S R

International Journal of

Advanced Multidisciplinary Scientific Research (IJAMSR) ISSN:2581-4281

\title{
Jean Watson's Middle Range Theory of Human Caring: A Critique
}

\author{
*Ms. Kholoud Najeh Alharbi, MSN, Dr. Omar Ghazi Baker, RN, PhD
}

*Ph. D Student \& Teaching Assistant, Nursing Administration and Education Department, College of Nursing, King Saud University, Riyadh, Saudi Arabia.

Associate Professor, Community, Psychiatric \& Mental Health Nursing Department, College of Nursing, King Saud University, Riyadh, Saudi Arabia.

Email: Kalharbil@ksu.edu.sa

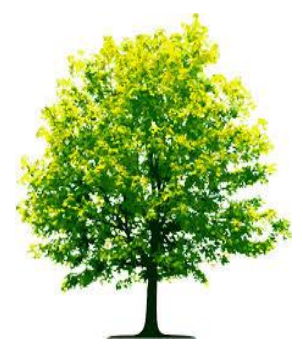

Keywords:

Entrepreneurial Skills, Integrated Learning of Science, Technology and Entrepreneurship.

\section{A B S T RA C T}

There are different terms that are related to care in the nursing profession such as nursing care, care, care giving.....etc (Blasdell, 2017). "Caring is a nurturing way of relating to a valued other toward whom one feels a personal sense of commitment and responsibility" (Swanson, 1991, p. 162). Dr. Jean Watson is a professor and nursing theorist and the director of the Watson Caring Science Institute. She is known for her Theory of Human Caring. Between 1975 and 1979, Watson established the Theory of Human Caring from her personal views of nursing. She developed this middle-range theory to combine nursing with education, practice and social psychology studies (Watson, n.d.). There are three main conceptual elements in both the original and evolving theory. The concepts are evolved based on Dr. Watson's experience and background. The three concepts of Watson's Theory of Human Caring include carative factors, a caring relationship, and caring moments. Watson defined the four nursing metaparadigm: person, health, environment, and nursing. Regarding the internal criticism, the Theory of Human Caring is adequate and all the concepts are understandable. However, some areas need improvement. Regarding the external criticism, there are many theories that are related to caring, but the Theory of Human Caring is a unique theory since it consists of carative factors and clinical caritas process. Finally, Watson's theory was widely utilized in clinical practice and research. Even though the theory is complex and abstract, it is suitable as a middle range theory for future nursing discipline.

Citation: Ms. Kholoud Najeh Alharbi, Dr. Omar Ghazi Baker (2020). Jean Watson's Middle Range Theory of Human Caring: A Critique. International Journal of Advanced Multidisciplinary Scientific Research (IJAMSR) ISSN:2581-4281, 3 (1), January 2020, pp 1- 14 
IJAMSR 3 (1) www.ijamsr.com CrossRef: https://doi.org/10.31426/ijamsr.2020.3.1.3011

\section{International Journal of \\ I J A M S R \\ Advanced Multidisciplinary Scientific Research (IJAMSR) ISSN:2581-4281}

\section{Introduction}

There are different terms that are related to care in the nursing profession such as nursing care, care, care giving.....etc (Blasdell, 2017). "Caring is a nurturing way of relating to a valued other toward whom one feels a personal sense of commitment and responsibility" (Swanson, 1991, p. 162). I selected theory of human caring because I believe that caring interaction between faculty members and students should be existed. "Caring in nursing education refers to faculty-student interaction based on ethical and human values" (Salehian, Heydari, Aghebati, \& Moonaghi, 2017, p. 257). My specialty is nursing education and I think caring should be integrated in the teaching process because it is very essential for faculty, students, colleagues to have an environment of support, peace, and self-esteem. "Facultystudent caring relationship in nursing education has been offered as enhancing students' learning experiences to care, the desire to care for others and self-actualization" (Salehian, Heydari, Aghebati, \& Moonaghi, 2017, p. 257).

\section{Biography of Nursing Theorist}

Dr. Jean Watson is a professor and nursing theorist and the director of the Watson Caring Science Institute. She is known for her Theory of Human Caring. Dr. Watson was born in West Virginia and she earned her Bachelor degree in nursing science from the University of Colorado in 1964. In 1966, she got her master of science in nursing in psychiatric and mental health nursing. Then, she completed her Ph.D. in Educational Psychology and Counseling at the same university. She has an experience in mental health nursing and caring science. Her research was mainly focused in human caring and loss. Between 1975 and 1979, Watson established the Theory of Human Caring from her personal views of nursing. She developed this middle-range theory to combine nursing with education, practice and social psychology studies (Watson, n.d.). At that time, her goal was to distinguish the nursing science from medical science by her theory of human caring. "According to Watson, caring is central to nursing practice, and promotes health better than a simple medical cure. She believes that a holistic approach to health care is central to the practice of caring in nursing" (Gonzalo, 2016, 
IJAMSR 3 (1) www.ijamsr.com CrossRef: https://doi.org/10.31426/ijamsr.2020.3.1.3011

\section{J A M S R}

\section{International Journal of Advanced Multidisciplinary Scientific Research (IJAMSR) ISSN:2581-4281}

p. 4). She wanted to prove that nursing is a unique discipline that has its own values, knowledge and practices. Watson was influenced by many Nursing theorists and philosophers such as: Nightingale, Henderson, and Martha Rogers (George, 2011). Her work also was affected by her teaching experience since her participation in developing nursing curriculum. Moreover, she was concerned about how nurses can express caring for their patients. In 1988, Watson published her theory and she did more than 20 books on caring which are used in clinical practice and education. She established a framework and called it "carative factors" in contrast to "curative factors" that mentioned in conventional medicine (Watson, n.d.). This paper will discuss analysis of the theory, internal criticism, external criticism, and the application of the nursing practice and education.

\section{Theory of Human Caring: Description and Concepts}

There are three main conceptual elements in both the original and evolving theory. The concepts are evolved based on Dr. Watson's experience and background. The three concepts of Watson's Theory of Human Caring include carative factors, a caring relationship, and caring moments.

The first concept is carative factors which is a guide for nursing practice (evolving toward clinical caritas processes). There are ten carative factors that provided a focus for nursing phenomena. The first factor is practicing loving kindness via a humanistic system of values. The second factor is sustaining the faith, hope, and belief system of oneself and those of others. The third factor is having an awareness or sensitivity to self and others. These three factors are considered foundation and basis for caring in nursing practice. The fourth factor is developing trusting relationships. The fifth factor is being supportive to the positive or negative feelings felt by self or others. The sixth factor is engaged in healing practice. The seventh is teaching and learning within a transpersonal caring relationship. The eighth carative factor is creating a healing environment. The ninth factor is assisting with the basic needs. The last factor is Opening to spiritual-mysterious. 
IJAMSR 3 (1) www.ijamsr.com CrossRef: https://doi.org/10.31426/ijamsr.2020.3.1.3011

\section{International Journal of} Advanced Multidisciplinary Scientific Research (IJAMSR) ISSN:2581-4281

"Clinical caritas" is transpersonal caring that moves from carative to caritas (Watson, n.d.). Watson described the transformation of the ten carative factors to the caritas process as the following:

- "Humanistic-altruistic values (will be): Practice of loving-kindness and equanimity for self and others" (Watson, 2007, p. 5).

- "Instilling/ enabling faith \& hope (will be): Being authentically/present to/enabling/ sustaining/ honoring the deep belief system and subjective life world of self/ others" (Watson, 2007, p. $5)$.

- "Cultivation of sensitivity to one's self and to others" (will be): Cultivation of one's own spiritual practices and being aware of self, and going beyond ego self" (Watson, 2007, p. 5).

- "Development of a helping-trusting, human caring relationship (will be): Developing and sustaining a helpingtrusting, authentic caring relationship" (Watson, 2007, p. 5).

- "Promotion and acceptance of the expression of positive and negative feelings" (will be): Being present to and supportive of the expression of positive and negative feelings" (Watson, 2007, p. $5)$.

- "Systematic use of a creative problemsolving, caring process" (will be): Creative use of self and all ways of knowing as part of the caring process (Watson, 2007, p. 5).

- "Promotion of transpersonal teachinglearning (will be): Engaging in genuine teaching-learning experience that attends to unity of being and meaning, attempting to stay within the other's frame of reference" (Watson, 2007, p. $5)$.

- "Provision for a supportive, protective, and/or corrective mental, physical, societal, and spiritual environment" (will be): "Creating healing environment at all levels, physical, nonphysical, subtle environment of energy and consciousness, whereby wholeness, beauty, comfort, dignity, and peace are potentiated" (Watson, 2007, p. 5). 
IJAMSR 3 (1) www.ijamsr.com CrossRef: https://doi.org/10.31426/ijamsr.2020.3.1.3011

\section{J A M S R}

\section{International Journal of Advanced Multidisciplinary Scientific Research (IJAMSR) ISSN:2581-4281}

- "Assistance with gratification of human needs" (will be): “Assisting with basic needs, with an intentional caring consciousness of touching and working with embodied spirit of individuals". (Watson, 2007, p. 5).

- "Allowance for existentialphenomenological-spiritual dimensions" (will be): "Opening and attending to the spiritual-mysterious, and existential dimensions of life-death; and soul care for self and the one-beingcared-for" (Watson, 2007, p. 5).

The second concept is a transpersonal caring relationship which means moving from the ego self to spiritual. Dr. Watson emphasized that nurses should take care of themselves before taking care of others. Establishing a trusting relationship will lead to healing (Watson, n.d.). "Transpersonal caring seeks to connect with and embrace the spirit or soul of the other through the processes of caring and healing and being in authentic relation, in the moment" (Watson, n.d, p. 6). In the trusting relationship, nurses should be conscious about the person's spirit and must enhance his/her dignity.
The third concept is a caring occasion or caring moment (Watson, n.d.). "A caring occasion occurs whenever the nurse and another come together with their unique life histories and phenomenal fields in a humanto-human transaction" (Watson, n.d, p. 9). A caring moment happens when there is an interaction between nurse and patient at the spirit level. This moment consists of feelings, verbal and nonverbal expressions. Usually this moment is based on a reflection of past and present experience and planned future. This moment will involve the spirit of both nurse and patient (Watson, n.d.).

\section{Diagram}

This diagram shows the three main concepts of Watson's Theory of Human Caring which includes (carative factors) that will access to human care transaction through (actual caring occasion, inter-subjective caring occasion, and a transpersonal caring moment) which will lead to possible outcomes (transcendence, harmony, and healing). 
IJAMSR 3 (1) www.ijamsr.com CrossRef: https://doi.org/10.31426/ijamsr.2020.3.1.3011
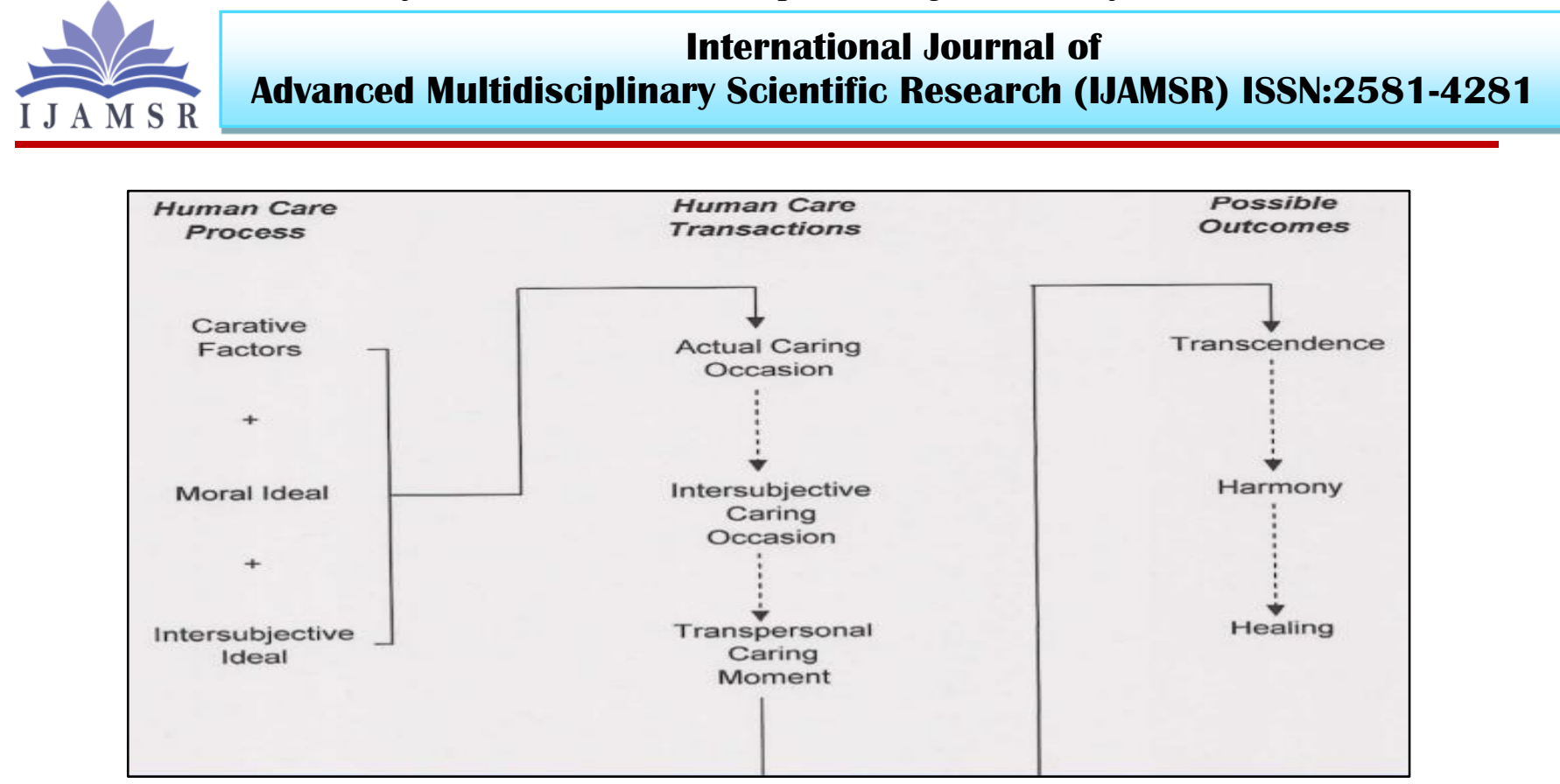

(Rufus, 2014, p. 24)

\section{Assumptions of the Theory}

Watson's Theory of Human Caring depends on seven assumptions as the following (Gonzalo, 2016):

- Caring effectively occurred only interpersonal (contact)

- Caring composed of carative factors that result in the fulfilment of specific human needs.

- Effectively caring, promotes the health of individual and family.
- Caring responses accept the current and future condition of the patient.

- A caring environment gives the opportunity for the patient to choose the best action for himself/ herself at specific time.

- Caring is integrated to curing

- Caring is the core of nursing practice

\section{Nursing Metaparadigm}

The four metapardigm of nursing are the following: person, health, environment, and nursing 
IJAMSR 3 (1) www.ijamsr.com CrossRef: https://doi.org/10.31426/ijamsr.2020.3.1.3011

\section{J A M S R}

\section{International Journal of Advanced Multidisciplinary Scientific Research (IJAMSR) ISSN:2581-4281}

\section{Person}

"The metaparadigm of person focuses on the patient who is the recipient of care" (Branch, Deck, Hiner, Holzwart, n.d., P. 123). Watson believes that each person has a unique needs and it should be met in a holistic approach which focus on mind, body, and spirit. Each person has the right to be understood and protected all the time (Branch, et al., n.d.).

\section{Health}

"The metaparadigm of health refers to the quality and wellness of the patient. It also includes the access the patient has to health care" (Branch, et al., n.d., p.123). Watson described the health as "more than simply curing an illness". "She believes that although curing is imperative, it is much more than a physiological response". (Branch, et al., n.d., p.124). To achieve health, nurses should use a holistic approach by balancing the physical, cognitive and spirit of the person. Also, she emphasized on the importance of the assessment of patients' needs to achieve optimal health (Branch, et al., n.d.).

\section{Environment}

"The metaparadigm environment includes both internal and external factors related to the patient" (Branch, et al., n.d., p.123). Environment can affect not only patients, also affects the nurse as well (Branch, et al., n.d.). Watson described the environment as a caring and healing space to maintain humanity and help others to overcome pain and illness (Alligood \& Tomey, 2010). In addition, Watson considered the policies and regulations as part of the environment (George, 2011).

\section{Nursing}

"This refers to the nurse and how he or she will apply their knowledge and skills when caring for patients. It also refers to the attributes of the nurse who is providing the care" (Branch, et al., n.d., p.123). Watson emphasized on the significance of building relationship between the nurses and clients. This relationship will help the nurses to gather more information from the patients to achieve better healing. Nurses should provide the care of their patients considering the physical, mental, and spiritual aspects. Nurse is a guide and advocacy for clients to achieve optimal health (Branch, et al., n.d.). 
IJAMSR 3 (1) www.ijamsr.com CrossRef: https://doi.org/10.31426/ijamsr.2020.3.1.3011

\section{J A M S R}

\section{International Journal of Advanced Multidisciplinary Scientific Research (IJAMSR) ISSN:2581-4281}

\section{Internal Criticism}

\section{Adequacy}

Does the theory address the required topic? (Barnum, 1990). "Watson partially meets the criteria for empirical adequacy for middle-range theories" (Short, n.d., p. 4). The Theory of Human Caring is adequate and all the concepts are understandable. However, some areas need improvement. "Watson is lacking published reports showing full empirical evidence of the effects of the Clinical Caritas Processes and the outcomes of a Transpersonal Caring Relationship" (Short, n.d., p. 4). Further research is needed to test the adequacy of the theory.

\section{Clarity}

Clarity is how the concepts of the theory stated and understood (Barnum, 1990). Dr. Watson explained the three concepts in an artful way. However, the theory is complex and person should read it very carefully so he/she can understand it very well. The terminology in the theory is not consistent. She used the word "transcendence" which is not common in the nursing field. She used her personal reflections to make the concepts easier (George, 2011).

\section{Consistency}

Does the theory's description, address the definition of the concept? Does the theory have congruent use of terms and interpretations? (Barnum, 1990). The Theory of Human Caring is not consistent because it has been called as Theory of Human Caring, the Caring Theory, and Transpersonal Caring which is confusing. Also, she used terms like "caring moment" and "caring occasion" which let the reader more confused (George, 2011).

\section{Logical development}

Does the theory logically follow a previous work that has been proved, or does it remains untested with its assumptions? (Barnum, 1990). Watson's Theory of Human Caring concentrated on the nurse-patient relationship. Watson's goal was to bring the attention to nursing as a unique and distinguish discipline. Her carative factors processed into the clinical caritas to keep more modern views (Watson, n.d.). 
IJAMSR 3 (1) www.ijamsr.com CrossRef: https://doi.org/10.31426/ijamsr.2020.3.1.3011

\section{J A M S R}

\section{International Journal of Advanced Multidisciplinary Scientific Research (IJAMSR) ISSN:2581-4281}

\section{Level of theory development}

"Is it consistent with the conceptualization of middle range theory?" (Barnum, 1990, p. 1). Watson's theory of human caring involves nursing as a whole, however, the caring moment is between nurse and patient. The Theory is focusing on the use of the clinical caritas processes and establishing a caring relationship between nurse and client in a caring setting (Watson, n.d.). Many researchers have been used theory of human caring as a theoretical framework in their studies. This theory is a complex but applicable as a middle-range theory.

\section{External Criticism}

\section{Complexity}

"How many concepts are involved as key components in the theory? How complicated is the description of the theory?" (Barnum, 1990, p.1). The theory is complex and it needs further explanation. The reader can understand and interpret the concepts in different ways based on their experience (George, 2011). The reader must think on an abstract level to be able to understand the theory. The words in theory moved from simple words to more complex words (Fawcett, 2005).

\section{Discrimination}

How unique is this theory to the area of nursing that it addresses? (Barnum, 1990, p. 1). There are many theories that are related to caring, but the Theory of Human Caring is a unique theory since it consists of carative factors and clinical caritas process. The theory involves the experience of both nurse and client. "Both come together in a caring moment that becomes part of the life history of each person" (Fawcett, 2005, p. 36). Also, the theory includes the unique dimensions which are mind- body-spirit (Fawcett, 2005). Moreover, "Watson's theory of nursing values and explicitly acknowledges multiple ways of knowing, including empirical, aesthetic, ethical, and personal knowing" (Fawcett, 2005, p. 36).

\section{Reality Convergence}

"Do these assumptions represent the real world? Do they represent the real world of nursing?" (Barnum, 1990, p. 1). Watson's theory has high reality convergence. "The authors recognized this convergence in Transpersonal Caring science" (Rosa, Horton-Deutsch, \& Watson, 2018, p. 24). Caring is the core concept in nursing practice. Nurses should be able to care of themselves and for others, especially for 
IJAMSR 3 (1) www.ijamsr.com CrossRef: https://doi.org/10.31426/ijamsr.2020.3.1.3011

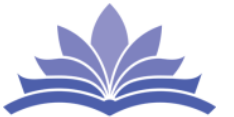

\section{International Journal of Advanced Multidisciplinary Scientific Research (IJAMSR) ISSN:2581-4281}

those who cannot take care of themselves. Caring definition by Watson is similar to the health promotion definition in WHO, caring involves "helping a person gain more selfknowledge, self-control, and readiness for selfhealing" (Fawcett, 2005, p. 42).

\section{Pragmatic}

The goal of Watson is to apply caring to real clinical settings. There are advantages and beneficial outcomes for both patients and nurses resulting from Watson's caring theory. "The initiative is part of Watson's Theory of Caring that not only considers those being cared for, but also the caregiver" (OnCourse Learning Corporation, 2018, p. 1). There are many hospitals established Relationship Based on Watson's theory. "Watson's theory also is part of Elmhurst (N.Y.) Hospital Medical Center's relationship-based care model" (OnCourse Learning Corporation, 2018, p. 1). They used this theory as a foundation for nursing practice.

\section{Scope}

"How broad or narrow is the range of phenomena that this theory covers?" (Barnum, 1990, p. 1). Watson's theory is abstract and that might be difficult for nurses who wants concrete formula to apply in their practice. It doesn't give a guideline for how nurses can develop caring relationships with their patients. This theory describes phenomena, concepts of metapradigms, and philosophy of science. This middle range theory is appropriate, but it is a complex and confusing theory for nurses because it is difficult to understand (Alligood \& Tomey, 2010).

\section{Significance}

Does the theory describe what nurses do? (Barnum, 1990). The theory is abstract and complex, however it has been used widely in nursing practice and research. "Many leaders and administrators in the nursing field have applied Watson's theories in hospitals around the country" (Branch, n.d., p.124). This theory has an impact on patients and nurses because it leads to high quality care.

\section{Utility}

"Is the theory able to be used to generate hypotheses that are researchable by nurses?" (Barnum, 1990, p. 1). This theory has benefits to the nursing practice and research. Researchers continue to use this theory as a theoretical framework even though it is complex and abstract. "Literature reviews demonstrate that Watson's Human Caring Theory is widely 
IJAMSR 3 (1) www.ijamsr.com CrossRef: https://doi.org/10.31426/ijamsr.2020.3.1.3011

used to guide nursing education, practice, and research internationally") Wei \& Watson, 2019, p. 17).

\section{Application of the Theory in Practice}

There are many researchers used Watson's theory of human caring in their studies. In 2017, Durgun \& Okumuş did a study on 86 Turkish women with infertility (45 within intervention group and 41 within the control group). Researchers wanted to examine the effectiveness of the nursing care based on Watson's theory in decreasing the anxiety level of coping when the infertility treatment fails. ThenIntervention group received nursing care program using the 10 carative factors of Watson caring theory. Seven follow ups are done by researchers and the period of the interview in each follow up was from 20 to $40 \mathrm{~min}$. Caring and healing process are applied to women in the intervention group to help them cope. However, women in the control group received standardized nursing care in the IVF center. The results of the study revealed that there are significant difference in anxiety, distress, and coping levels between the intervention and control group. The anxiety scores in the intervention group decreased by thirteen points and distress reduced by fourteen points. Watson's theory of human caring was a guide for IVF center and provided a high quality care to women with infertility. Application of the theory to the nursing care helped to decrease anxiety and distress levels among females with infertility and also increased the coping among women when the infertility treatment failed (Durgun \& Okumuş, 2017).

In 2017, a study done by Tektaş \& Çam to see the effects of nursing care based on Watson's theory on the mental health of pregnant women after a pregnancy loss. The sample size was 128 participants from maternity polyclinics of two university hospitals in Izmir, Turkey. The intervention group received nursing care that includes the ten carative factors of Watson's theory and the control group didn't receive a nursing care in the outpatient clinic. Beck anxiety scale, Beck hopeless scale, Beck depression scale was used to measure the anxiety, hopelessness, and depression level. Results and conclusion: there is a significant difference between the mean scores of anxiety ( $p$ value: 0.930 ), hopelessness ( $p$ value: 0.124 ), depression ( $\mathrm{p}$ value: 0.609), and prenatal 
IJAMSR 3 (1) Www.ijamsr.com CrossRef: https://doi.org/10.31426/ijamsr.2020.3.1.3011

\section{J A M S R}

\section{International Journal of Advanced Multidisciplinary Scientific Research (IJAMSR) ISSN:2581-4281}

attachment ( $\mathrm{p}$ value: 0.362 ) between women in the intervention and control groups. Nursing care based on Watson's Theory is effective for the mental health of pregnant women after pregnancy loss (Tektaş \& Çam, 2017).

In 2014, Arslan, Okumuş, \& Buldukoğlu, did a study to examine the effects of nursing care based on Watson's Theory on distress, selfefficacy and adjustment in infertile women. The sample size was 105 Turkish women with infertility (52 was in the intervention group and 53 was in the control group). The intervention group received nursing care based on Waston's theory using caritas process and the control group had standard nursing care. The results of the study revealed that an improvement in selfefficacy score by seven points, adjustment score by seven points, and infertility distress scores ( $p$ value: 0.001). However, there was no improvement in the control group. Conclusion: nursing care based on Watson's theory had a positive effect on distress, adjustment, and selfefficacy among women with infertility.

\section{Conclusion}

Watson's goal was to distinguish nursing from other professions. She created Theory of Human Caring based on her personal view. Watson's theory was widely utilized in clinical practice and research. Even though the theory is complex and abstract, it is suitable as a middle range theory for future nursing discipline. "When human caring is applied in interprofessional teams, healthcare professionals find a caring consciousness to care for oneself and each other, and thus promote patient care") Wei \& Watson, 2019, p. 23). 
IJAMSR 3 (1) www.ijamsr.com CrossRef: https://doi.org/10.31426/ijamsr.2020.3.1.3011

\section{References}

1) Alligood, M. R. (2018). Nursing theorists and their work: Theory of caring. St Louis, Mo: Mosby. ISBN: 9780323402248

2) Alligood, M. R., \& Tomey, A. M. (2010). Nursing theorists and their work (7th ed.). Maryland Heights, MO: Mosby Elsevier.

3) Arslan, Ö. İ., Okumuş, H., \& Buldukoğlu, K. (2014). A randomized controlled trial of the effects of nursing care based on Watson's Theory of Human Caring on distress, self-efficacy and adjustment in infertile women. Journal of Advanced Nursing (John Wiley \& Sons, Inc.), 70(8), 1801-1812. https://doi-

org.sdl.idm.oclc.org/10.1111/jan.12338

4) Barnum, B. J. (1990). Nursing theory: Analysis, application, evaluation. Glenview, IL: Scott Foresman/Little, Brow.

5) Blasdell, N. (2017). The Meaning of Caring in Nursing Practice. Retrieved from

file://C:/Users/Kholoud/Downloads/art icle-IJNCP-238.pdf

6) Branch, C., Deck, H., Hiner, C., Holzwart, T. (n.d.). Four nursing metaparadigms. Retrieved from file:///C:/Users/Kholoud/Downloads/22 199-Article\%20Text-50307-1-10-

20160621\%20(1).pdf
7) Durgun Ozan, Y., \& Okumuş, H. (2017). Effects of nursing care based on Watson's theory of human caring on anxiety, distress, and coping, when infertility treatment fails: A randomized controlled trial. Journal of caring sciences, 6(2), 95-109. doi:10.15171/jcs.2017.010

8) Fawcett, J. (2005). Contemporary Nursing Knowledge: Analysis and Evaluation of Nursing Models and Theories. Philadelphia: F. A. Davis Company.

9) George, J. B. (2011). Nursing theories: The base for professional nursing practice (6th ed.). Upper Saddle River, NJ: Pearson Education.

10) Gonzalo, A. (2016). Jean Watson: Theory of Human Caring. Retrieved from https://nurseslabs.com/jeanwatsons-philosophy-theorytranspersonal-caring/

11) OnCourse Learning Corporation. (2018). Local hospitals embrace Jean Watson's caring theory. Retrieved from https://www.nurse.com/blog/2010/06/1 4/local-hospitals-embrace-jeanwatson\%C2\%92s-caring-theory/

12) Rafael, A.R. (2000). Watson's philosophy, science, and theory of human caring as a conceptual framework for guiding community health nursing practice. Advances in Nursing Science, 23(2), 34-49.

13) Rosa, W., Horton-Deutsch, S., \& Watson, J. (2018). A handbook for caring science: Expanding the paradigm. Springer Publishing Company. 
IJAMSR 3 (1) www.ijamsr.com CrossRef: https://doi.org/10.31426/ijamsr.2020.3.1.3011

14) Rufus, D. (2014). Watson theory. Retrieved from https://www.slideshare.net/DelightsonR ufus/watson-theory

15) Salehian, M., Heydari, A., Aghebati, N., \& Karimi Moonaghi, H. (2017). Faculty-student caring interaction in nursing education: An integrative review. Journal of caring sciences, 6(3), 257-267. doi:10.15171/jcs.2017.025

16) Short, M. (n.d). Jean Watson the philosophy and science of caring By Amanda Buisman and Stephanie Kimbrel. Retrieved from https://slideplayer.com/slide/8909095/

17) Tektaş, P., \& Çam, O. (2017). The effects of nursing care based on Watson's theory of human caring on the mental health of pregnant women after a pregnancy loss. Archives of Psychiatric Nursing, 31(5), 440-446. https://doiorg.sdl.idm.oclc.org/10.1016/j.apnu.20 17.07.002

18) Wei, H., \& Watson, J. (2019). Healthcare interprofessional team members' perspectives on human caring: A directed content analysis study. International journal of nursing sciences, 6(1), 17-23.

19) Watson, J. (n.d.). Theory of Human Caring. Retrieved from http://www.watsoncaringscience.org/in dex.cfm/feature/84_12/theory-ofhuman-caring.cfm
20) Watson, Jean. (2007). Watson's theory of human caring and subjective living experiences: Carative factors/caritas processes as a disciplinary guide to the professional nursing practice. Texto \& Contexto - Enfermagem, 16(1), 129135. https://dx.doi.org/10.1590/S010407072007000100016 